[Aus dem Michailowschen Krankenhaus in Tiflis.]

(Vorstand: A. G. Gurko.)

\title{
Zur Frage über die Kultur des Plasmodiums der tropischen Malaria nach Bass und Johns. Vorläufige Mitteilung. ${ }^{1}$
}

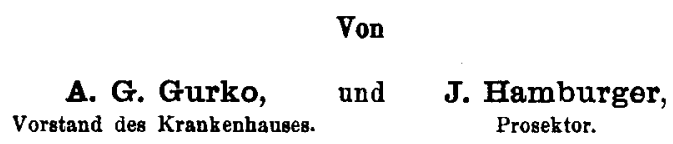

Die Kenntnis des Parasiten der Malaria stützte sich bis jetzt einerseits auf das Studium seiner Morphologie, das dank der Färbungsmethode nach Romanowsky sehr bequem schien, und anderseits auf die Beobachtung seines Lebens im Organismus des Anopheles. Alle Versuche einen künstlichen Nährboden zu finden, in welchem es möglich wäre das Leben und die Vermehrung des Parasiten zu studieren, waren bis jetzt erfolglos. Unter den in dieser Richtung gemachten Beobachtungen verweisen wir auf die sehr interessanten Experimente Sacharoff's (1), welcher während 7 Tagen im Eis einen Blutigel mit Malariablut getränkt konservierte. Dr. Sacharoff überzeugte sich von der Möglichkeit während dieser Zeit das Leben des Plasmodiums zu erhalten in folgender Weise: bei den Parasiten blieben die amöboiden Bewegungen erhalten, und schlieBlich impfte Dr. Sacharoff sich das Blut des Blutigels ein und bekam Malaria-Anfälle. Unter den erfolglosen Versuchen der PlasmodiumKultur können wir auf die von Coronado (2) und $K u$ baroff (3) verweisen. In den bekannten Monographien von Ruge (4), Grall und Clarak (5), Marzinowsky (6) u. a. wird von der Kultur der Plasmodien gar nichts erwähnt. In der neuen Auflage der Monographie ron Ruge (7) findet sich

1 Vortrag, gehalten in der Kaiserl. kaukas. Medizin. Gesellschaft 8./21. I. 1913. 
eine kurze Anmerkung, daB es im Jahre 1912 Bass gelungen ist drei Formen der Malariaparasiten in defibriniertem Blut oder in Blut gemischt mit Natrium citricum bei anaeroben Bedingungen zu kultivieren. In der Münchener med. Wochenschrift (8) erschien im Jahre 1912 (Nr. 48) eine Abhandlung von Olpp über die Reinkultur von Malariaparasiten nach Bass und Johns.

Bass und Johns wurden von der New-Orleans-Universität nach Ankona am Panama-Kanal geschickt, und es ist ihnen dort gelungen, die Reinkultur der Parasiten in 29 Fällen von Malaria tropica und sechs Fällen der Tertiana zu bekommen. Während dieser Arbeit in Ankona im Jahre 1912 haben die genannten Autoren entdeckt, daB es für ein erfolgreiches Wachstum der Parasiten nötig ist, dem defibrinierten Blut Dextroselösung in einem bestimmten Prozent zuzusetzen, manchmal auch Maltose, während andere Zuckerarten sich nicht eigneten. Bass unterscheidet zwei Methoden der Kultivierung; bei der einen bekommt man nur eine Generation, bei der anderen beliebig viel Generationen.

Nach der ersten Methode füllt man in einen sterilen Glaszylinder von $21 /_{2}$ em Durchmesser, welcher mit einem bis zum Boden reichenden Glasstab beschickt ist, $1 / 10^{\mathrm{cem}} 50$ prozent. Dextroselösung; darauf entzieht man einem Malariapatienten, am zweckmäBigsten 1 bis 2 Stunden, nachdem er eine gute Mahlzeit zu sich genommen hat, aus einer Armvene mit einer 10 bis $20^{\circ \mathrm{cm}}$ haltenden Glasspritze und Nadel von relativ groBem Durchmesser Blut, von dem man sofort $10^{\mathrm{ccm}}$ unter möglichster Vermeidung von Luftbeimengung dem Inhalt des schräg gehaltenen Dextrosezylinders hinzugefügt. Durch vorsichtige Bewegungen mit dem Glasstab wird das Blut zur Gerinnung gebracht, wobei wieder darauf geachtet werden muB, daB keine Luftblasen entstehen. Man kann auch diese Mischung sofort in den Thermostat bei 40 bis $41^{\circ} \mathrm{C}$ stellen. In jedem Falle muB die Blutsäule $21 / 2$ bis $5^{\mathrm{cm}}$ hoch sein; ist sie kleiner als $12 \mathrm{~mm}$, so sterben die Parasiten oft vor der Schizogonie ab. Die Plasmodien leben und entwickeln sich an der oberen Grenze der präzipitierten Blutkörperchen in einer Schicht von 1 bis $5^{\mathrm{mm}}$ Dicke. In der Ruhestellung wachsen die Kulturen bei jeder Temperatur zwischen 37 bis $41^{\circ} \mathrm{C}$. Der Tropicaparasit, Plasmodium immaculatum, hat sein Optimum bei $41^{\circ} \mathrm{C}$. Bei dieser Temperatur gelangen derartige Parasiten mit großer Regelmäßigkeit zur Teilung. Läßt man die Kultur lănger stehen, so werden die Parasiten durch das Serum und die Leukozyten vernichtet.

Um mehrere Generationen zu bekommen, hat Bass folgendes Verfahren vorgeschlagen: es werden die Leukozyten aus dem Medium entfernt, und es wird eine neue Portion frischer Blutkörperchen zugesetzt. Die letzte Ṁethode haben wir in zwei Fällen von Malaria tropica versucht 
In einen sterilen Kolben gossen wir $10^{\mathrm{ccm}}$ Blut, welches aus der Vena mediana eines Kranken mit Malaria tropica genommen wurde, defibrinierten es und zentrifugierten mittels einer elektrischen Zentrifuge 10 Minuten lang (2000 Umdrehungen pro Minute). Dann wurde in ein steriles Reagenzglas ( $1 \frac{1}{2}{ }^{\mathrm{em}}$ Diam.) $1 / 10{ }^{\mathrm{cm}}$ der 50 prozentigen Dextroselösung eingegossen und vorsichtig 2 cen des von uns gewonnenen Serums zugesetzt; danach wurde mit der Pipette auf den Boden des Reagenzglases $1 / 10 \mathrm{~cm}$ zentrifugierter Erithrozyten eingebracht. Die Plasmodien aus diesem Reagenzglas wurden in folgender Weise umgepflanzt. In 'ein neues Reagenzglas wurde $1 / 10^{\mathrm{com}}$ der 50 prozentigen Dextroselösung und $2^{\mathrm{cem}}$ Serum gegossen, danach wurde mit einer Pipette (Inhalt $1 \mathrm{~cm}$ mit 100 Teilungen) $\mathbf{0 . 0 5} \mathbf{c c m}$ der infizierten Erithrozyten aus der ersten Kultur genommen und, nachdem in dieselbe Pipette fünfmal soviel gesunde Blutkörperchen (also $0.25^{\mathrm{cm}}$ ) aufgesogen waren, die ganze Mischung auf den Boden des neuen Reagenzglases transplantiert. Bei neueren zwei Fällen ron Malaria tropica haben wir drei Versuche gemacht.

Erster Fall. Knabe, 8 Jahre alt, wurde aus einer stark verseuchten Malariagegend (Station Schagali der transkaukasischen Eisenbahn) am 8. Dezember 1912 in das Krankenhaus eingeliefert. Der Vater des Knaben, welcher mit ihm zugleich nach dem Krankenhause gebracht wurde, starb sehr bald an chronischer Malaria. Der Knabe ist sehr abgemagert, mit gelblicher bleicher Haut, die Milz tritt drei Querfinger über den Rippenbogen hervor und ist derb; die Leber tritt zwei Querfinger breit hervor und ist ebenfalls derb. Die Lungen und das Herz sind normal. Temperatur beim Eintritt in das Krankenhaus $37 \cdot 4^{\circ} \mathrm{C}$, in den nachfolgenden drei Tagen gegen $39^{\circ} \mathrm{C}$ und nachdem zwischen 37.4 und $37.6^{\circ}$. Das Blut wurde während der Apyrexie bei einer Temperatur von $37 \cdot 4^{0} \mathrm{C}$ am Tage des Eintritts entnommen. Im Blute wurden die ringförmigen und halbmondförmigen Formen des Parasiten der tropischen Malaria gefunden. Nachdem das Reagenzglas mit dem Blute dieses Knaben nach der oben beschriebenen Methode infiziert war, hielten wir es drei Tage im Thermostat bei einer Temperatur von $39^{\circ} \mathrm{C}$. Nach 15 Stunden des Wachstums haben wir Ringe in großer Zahl, Halbmondformen und sich teilende Schizonten gefunden, nach 40 Stunden wenig Ringe und mehr Gameten; nach 64 Stunden schöne Figuren der sich teilenden Schizonten und wenig Ringe. Aus diesem ersten Reagenzglas wurde schon nach den ersten 15 Stunden eine Umpflanzung in ein zweites Reagenzglas gemacht, und nach 24 Stunden wurden die Merozoiten in grober Zahl gefunden. Aus diesem Reagenzglas oder der zweiten Generation wurde noch eine Umpflanzung in ein drittes Reagenzglas gemacht, und nach 24 Stunden konnten wir in dieser zweiten Umpllanzung, d. h. der dritten Generation kleinste Merozoiten und Gameten nachweisen. Eine vierte Generation konnten wir nicht bekommen. Es sei bemerkt, daB in diesem Falle der Kranke niemals Chinin bekommen hatte.

Zweiter Versuch. Von demselben Kranken wurde am 16. Dezember Blut genommen, nachdem er während der ersten vier Tage nach seiner Auf- 
nahme innerlich je $0.6 \mathrm{grm}$ Chin. muriat, während der nachfolgenden vier Tage unter die Haut je $0.5 \mathrm{grm}$ erhalten hatte. Nunmehr konnte man im Blute keine Ringe mehr, aber noch Halbmondformen nachweisen. Die Züchtung gelang nicht.

Dritter Versuch (Zweiter Fall). Einem anderen Kranken mit Malaria tropica, der früher schon mit Chinin behandelt war, wurde das Blut bei subnormaler Temperatur entnommen, und das gleiche Verfahren angewandt. Die Züchtung gelang nicht, obgleich im Blute auBer Halbmondformen auch Ringformen, wenn auch nur in sehr geringer Menge nachgewiesen waren.

Es sei bemerkt, daß die Jahreszeit die ungeeignetste für Malariauntersuchungen war, und daB deshalb die Zahl unserer Beobachtungen zu klein ist, um irgendwelche Schlüsse über die Ursachen des Mißgelingens der Kultur zu ziehen. Es sei aber betont, daB der erste Kranke zur Zeit des zweiten Versuchs mit Chinin 8 Tage behandelt war, und daB der zweite Kranke ebenfalls schon Chinin erhalten hatte. Nur im ersten Versuch, wo der Kranke vorher überhaupt noch nicht behandelt war, ist die Kultur gelungen; es scheint also, daB die vorherige Behandlung mit Chinin das Kultivieren der Plasmodien nach der oben genannten Methode unmöglich macht. Vielleicht ist auch nicht jedes Blut des gesunden Menschen als Nährboden für die Plasmodien passend, was schon Bass bemerkt hat. Technisch ist es auch nicht leicht, die Bedingungen der strengen Anaërobiose bei der Einbringung des Blutes mit der Pipette zu erfüllen. AuBerdem bemerkt $0 \operatorname{lpp}$, daB es manchmal Bass und Johns nicht möglich war einen Erfolg zu bekommen, wenn das Blut von fastenden Menschen genommen wurde.

In dem ersten Versuch, in dem es uns gelungen ist, eine Reinkultur in drei Generationen zu bekommen, haben wir in das Reagenzglas Blut eingesät, in welchem nur ringförmige Plasmodien und Gameten nachzuweisen waren; aber in der Kultur haben wir die typischen Merozoiten in großer Zahl (bis 4 Merozoiten in einem Blutkörperchen bei der 3. Generation) und die Figuren der sich teilenden Schizonten bekommen. Es ist klar, daB die Schizogenie in dem Reagenzglas verlief. Dabei sei bemerkt, $\mathrm{daB}$ das Blut der $\mathbf{3}$. Generation $\mathbf{3 6}$ mal verdünnt war. Mit anderen Worten, wir haben in der Kultur denselben ProzeB beobachtet, welcher normalerweise bei Malaria tropica (non perniciosa!) in den Kapillaren des Knochenmarks, der Milz und des Zentralnervensystems, nicht aber in den peripheren BlutgefäBen verläuft. Weitere Beobachtungen in dieser Richtung sind im Gange. 


\section{Literatar-Verzeichnis.}

1. Sacharoff, Über den Einflub der Kälte anf die Lebensfähigkeit der Malariaparasiten. Centralblatt für Bakteriologie. Bd. XV. Nr. 5 u. 6.

2. Coronado, Reproducion del hematozoario di Laveran. Cronica med. quirurg. d. Habana. 1892. Nr. 22. - Ref. Centralblatt für Bakteriologie. 1892. Bd. XIII.

3. Cubaroff, Die Pilzchen der Malaria.

4. Ruge, Handbuch von Kolle und Wassermann. 1903. Bd. I.

5. Grall et Clarak, Traité des maladies exzotiques.

6. Mikrobiologie von Marzinowsky. 1. Aufl. Bd. I.

7. Ruge, Handbuch von Kolle und Wassermann. 2. Aufl. Bd. VII,

8. Olpp, Bass und Johns, The Cultivation of Malariae Plasmodia in vitro. Journal of experiment. med. 1912. Vol. XVI. p. 567. 